\title{
BMJ Open Causes of death in patients with Itai-itai disease suffering from severe chronic cadmium poisoning: a nested case- control analysis of a follow-up study in Japan
}

Muneko Nishijo, ${ }^{1,2}$ Hideaki Nakagawa, ${ }^{3}$ Yasushi Suwazono, ${ }^{4}$ Kazuhiro Nogawa, ${ }^{4}$ Teruhiko Kido ${ }^{5}$

To cite: Nishijo M, Nakagawa H, Suwazono $\mathrm{Y}$, et al. Causes of death in patients with Itaiitai disease suffering from severe chronic cadmium poisoning: a nested casecontrol analysis of a follow-up study in Japan. BMJ Open 2017;7:e015694. doi:10.1136/ bmjopen-2016-015694

- Prepublication history and additional material are available. To view these files please visit the journal online (http://dx.doi. org/10.1136/bmjopen-2016015694).

Received 22 December 2016 Revised 8 June 2017 Accepted 9 June 2017

\section{CrossMark}

${ }^{1}$ Department of Public Health, Kanazawa Medical University, Uchinada, Ishikawa, Japan

${ }^{2}$ Health Evaluation Center, Kanazawa Medical University Hospital, Uchinada, Ishikawa, Japan

${ }^{3}$ Institute of Medical Science, Kanazawa Medical University, Uchinada, Ishikawa, Japan ${ }^{4}$ Department of Occupational and Environmental Medicine, Graduate School of Medicine, Chiba University, Chiba, Japan ${ }^{5}$ Department of Community Health Nursing, School of Health Sciences, Kanazawa University, Kanazawa, Japan

Correspondence to Dr Muneko Nishijo; ni-koei@ kanazawa-med.ac.jp

\section{ABSTRACT}

Objective To clarify the causes of deaths among patients with Itai-itai disease and severe cadmium (Cd) poisoning. Design Nested case-control analysis of a populationbased cohort study.

Setting Database of patients with Itai-itai disease and residents of $\mathrm{Cd}$-polluted areas, maintained by the Ministry of Environment, Japan.

Participants Subjects included 142 women with Itaiitai disease, 111 women with $\mathrm{Cd}$-induced renal tubular dysfunction and 253 controls matched for sex, age and occupation. All subjects participated in a health impact survey between 1979 and 1984 and were followed until 30 November 2005.

Main outcomes and measures Adjusted HRs with 95\% Cls for cause of death in women with Itai-itai disease and screened female cases with tubular dysfunction were compared with matched pair controls, using Cox's proportional hazard model. Vital statistics data were used to determine cause of death. Direct causes of death from autopsy records were used in 29 patients who died from Cd poisoning.

Results The most common cause of death among patients with Itai-itai disease was pneumonia, with a significantly increased adjusted HR of 4.54 (95\% Cl 2.65 to 7.76). Renal diseases were the most common cause of death in renal tubular dysfunction cases, with an increased HR of 12.0 (95\% $\mathrm{Cl} 3.92$ to 36.8). The adjusted HR for renal diseases was also significantly increased in patients with Itai-itai disease (19.49 (95\% Cl 6.43 to 59.09)), with a greater impact on mortality of patients with Itai-itai disease than screened cases. The HR for gastrointestinal (GI) diseases was significantly increased $(13.79(95 \% \mathrm{Cl} 3.87$ to 49.10$))$ in patients, especially in the first 10 years (37.1 (4.81 to 286.0)). Conclusions Among patients with Itai-itai disease, pneumonia and Gl diseases contributed to increased mortality risk. Renal disease is also a significant mortality risk in patients with Itai-itai disease and women with renal tubular dysfunction.

\section{INTRODUCTION}

Itai-itai disease is caused by cadmium $(\mathrm{Cd})$ exposure, produced as a result of human
Strengths and limitations of this study

- Data linkage with autopsy records enabled us to distinguish the true medical features at the end of life among patients with severe cadmium (Cd) poisoning.

- Differences in cause of death were clarified between screened cases with renal tubular dysfunction and patients with Itai-itai disease.

- The direct causes of death in $18(12.7 \%)$ patients with Itai-itai disease remained $\mathrm{Cd}$ poisoning, because of lack of autopsy records.

activities related to industrialisation, and this condition was first recognised in Japan in the 1960s. ${ }^{12}$ Itai-itai disease is characterised by osteomalaecia with severe bone pain and is associated with renal tubular dysfunction. ${ }^{1-3}$

Itai-itai disease mainly affects women residing in rice farming areas irrigated by the contaminated Jinzu River in Toyama, Japan. ${ }^{1-3}$ As of 28 December 1999, 410 patients were officially diagnosed or suspected of having Itai-itai disease. ${ }^{4}$ Since then, 380 patients have died of the condition; 85 of these patients underwent autopsies performed in Toyama University Hospital. ${ }^{5}$ As recently as 2000, 20 new cases ( 1 man and 19 women) were officially recognised by the local government of Toyama. ${ }^{6}$ These cases reflect a large Cd body burden originated from past environmental Cd exposure.

An epidemiological survey conducted between 1967 and 1968 revealed the largest-scale epidemic of $\mathrm{Cd}$ pollution-induced Itai-itai disease in the world, affecting individuals $\geq 30$ years of age residing in the Jinzu River basin in Toyama. ${ }^{2}$ Women with Itaiitai disease participated in the survey and were followed for 15-20 years. As a result, it 
was noted that these women had an increased mortality rate compared with residents who had no clinical urinary findings. ${ }^{78}$ However, their causes of death were not investigated in these follow-up studies.

In previous studies of residents in Cd-polluted areas, identified the causes of deaths contributing to increased mortality were renal diseases, ${ }^{9-11}$ stroke $^{10-13}$ and cancer. ${ }^{14}$ Increased cancer mortality is a significant research interest, because $\mathrm{Cd}$ and its compounds are classified as human carcinogens by the International Agency for Research on Cancer (IARC). ${ }^{15} 16$ However, in Japanese cohort studies in the Cd-polluted Kakehashi River basin, no increased cancer mortality risk has been reported, with the exception of increased cancer mortality during the first 5-year observational period in women with renal tubular dysfunction. ${ }^{10} 1113$ Recently, we conducted a 26-year follow-up of residents aged $\geq 50$ years in the Jinzu River basin, an endemic area of Itai-itai disease, and non-polluted areas in Toyama Prefecture, who participated in the first stage of health impact survey conducted by the Ministry of Environment in Japan to screen people at a risk of Itai-itai disease from 1976 to $1984 .{ }^{17}$ After determining the causes of death by successful data linkage with vital statistics data, we found that 267 women with renal tubular dysfunction in the Cd-polluted Jinzu River basin showed an increased mortality risk from cancer, ischaemic heart diseases and renal diseases compared with women in non-polluted areas. ${ }^{18}$

A total of 142 female patients with Itai-itai disease were included in this cohort study, but the cause of death in 47 patients could not be distinguished, because Cd poisoning was reported as their cause of deaths in vital statistics data. Therefore, we used the direct causes of death listed in autopsy records ${ }^{5}$ for these patients in the primary cohort study of a 26-year follow-up and performed a nested casecontrol analysis of the mortality risk for main causes of death in patients with Itai-itai disease. Additionally, we compared the causes of death in screened cases with renal tubular dysfunction in the early stages of Itai-itai disease, with those in typical patients, the severest form of Cd poisoning ever reported in the world.

\section{MATERIALS AND METHODS Study subjects}

A total of 9446 participants (4289 men, 5157 women) in the first stage of the health impact survey in Toyama, conducted by the Ministry of Environment between 1979 and 1984, were targeted in the 26-year follow-up survey (the primary cohort study). This included $97.6 \%$ of all inhabitants aged $\geq 50$ years. ${ }^{16}$ Participants in the health impact survey included residents who lived in the Cd-polluted Jinzu River basin (3363 men, 3985 women, 7348 total) and controls from non-polluted areas in the same prefecture (926 men, 1172 women, 2098 total). In the health impact survey, information regarding residency, smoking and drinking habits and history of diseases, including hypertension and Itai-itai disease, were obtained using a structured questionnaire. ${ }^{17}$

A total of 142 women with Itai-itai disease were identified among the subjects of the primary cohort study and were confirmed to have the disease. ${ }^{7}$ Women screened by glucosuria and proteinuria were invited to be examined for levels of urinary $\beta 2$-micloglobulin $\left(\beta_{2}-\mathrm{MG}\right)$ and/ or lysozyme and urinary $\mathrm{Cd}$ after the first stage of the screening survey. As a result, 111 cases of impaired renal tubular function were identified and confirmed using clinical tests of per cent tubular reabsorption of phosphate and creatinine clearance. A total of 253 controls matched for sex, age and occupation were selected for 142 patients with Itai-itai disease and 111 screened cases of renal tubular dysfunction. Age distribution, smoking rates and history of hypertension among patients with Itai-itai disease, screened cases and controls are shown in table 1 .

Table 1 Adjusted HRs for all causes in women with Itai-itai disease and screened women with renal tubular dysfunction compared with controls matched for sex, age and occupation

\begin{tabular}{|c|c|c|c|}
\hline Groups & Controls & Screened cases & $\begin{array}{l}\text { Patients with Itai-itai } \\
\text { disease }\end{array}$ \\
\hline Number of subjects & 253 & 111 & 142 \\
\hline Number (\%) of hypertensions & $52(20.1)$ & $27(24.1)$ & $25(17.7)$ \\
\hline Number (\%) of smokers & $6(2.4)$ & $3(2.7)$ & $3(2.1)$ \\
\hline $\mathrm{HR}(95 \% \mathrm{Cl})$ & 1.00 & $1.50(1.17$ to 1.91$)$ & $2.68(2.15$ to 3.35$)$ \\
\hline \multicolumn{4}{|l|}{ A 10-year follow-up } \\
\hline Number of deaths & 95 & 48 & 94 \\
\hline $\mathrm{HR}(95 \% \mathrm{Cl})$ & 1.00 & 1.60 (1.13 to 2.27$)$ & 2.85 (2.13 to 3.80$)$ \\
\hline
\end{tabular}

Covariates, age at baseline, smoking status at present (yes: 1, no: 0) and hypertension history (yes: 1, no: 0). 
The follow-up survey in the primary cohort study

We collected family registry records of all subjects from the Koseki system and determined their survival status (alive or dead) as of 30 November 2005 and the date of death. The cause of death was obtained from vital statistics data linked to health survey data, with survival status based on birth date, date of death, sex and address. ${ }^{17}$ A total of 166 subjects $(1.7 \% ; 133$ exposed and 33 controls) were lost to follow-up during the observation period because their status could not be determined. In all areas, 5351 deaths occurred. The cause of death was determined for 5276 cases $(98.5 \%$ of deaths) by successful data linkage and classified according to the 9th revised International Classification of Diseases (ICD 9) from 1979 to 1994 and the ICD 10 from 1995 to 2005 (see online supplementary table 1). Additionally, Itai-itai disease was included in Cd poisoning (985.5 of ICD 9, T56.3 of ICD 10).

\section{Data linkage with autopsy records of patients with Itai-itai disease}

We found that 29 patients who died from Cd poisoning, according to vital statistics, were reported in the list of autopsy records of patients with Itai-itai disease. ${ }^{4}$ Therefore, we used direct causes of death in autopsy records for their causes of death in the present analysis, which were shown in online supplementary table 2 after dividing into two groups according to the survival period $(<$ and $\geq 10$ years of observation).

\section{Mortality analysis}

To indicate mortality during the early observational period, the rate $(\%)$ of deaths for the first 10 years (early death rate) and that for the total years of observation were calculated for each cause of death. The number of early deaths was calculated for the first 10-year observation period from baseline to 31 December 1990.

We performed a nested case-control analysis to assess the mortality risk for the primary causes of death in female patients with Itai-itai disease and female screened cases with renal tubular dysfunction, compared with healthy controls matched for sex, age and occupation at the baseline survey. For this analysis, we used a Cox's proportional hazard model after adjusting for three confounding variables (age, smoking status at present (yes: 1, no: 0 ) and history of hypertension (yes: 1, no: 0)). All analyses were performed using SPSS version 21.0 software (IBM, Armonk, New York, USA). $p$ Values of $<0.05$ were considered statistically significant.

\section{Patient involvement}

Our study was a secondary data analysis of a cohort study, which did not include patients as study participants. No patients were involved in establishing the research question or the outcome measures nor were any involved in the design and implementation of the study. The present results will be disseminated to the general public through the Ministry of Environment in Japan.

\section{RESULTS}

\section{Mortality for all causes}

The number of deaths occurring during the 26-year follow-up and those during the first 10-year observational period are shown in table 1 , along with the corresponding early death rates. During the 26-year follow-up, 139 patients with Itai-itai disease $(97.9 \%)$ and 98 screened cases of renal tubular dysfunction $(88.3 \%)$ died, with significantly increased HRs for all causes compared with controls $(79.8 \%)$ who died during the same period. The adjusted HR (95\% CI) was 2.68 (2.15 to 3.35 ) in patients with Itai-itai disease and 1.50 (1.17 to 1.91) in screened cases. During the first 10-year observation period, 94 patients $(67.6 \%)$ with Itai-itai disease died (HR 2.85 (2.13 to 3.80$)$ ); however, less than $50 \%$ of screened cases (HR 1.60 (1.13 to 2.27)) and controls died.

\section{Mortality for primary causes of death during the 26-year follow-up}

Adjusted HRs of mortality for primary causes of death of patients with Itai-itai disease, compared with controls and screened cases, are shown in table 2. The three most common causes of death among patients with Itai-itai disease were respiratory diseases, cardiovascular diseases and kidney and urinary tract diseases. However, the increased HR for kidney and urinary tract diseases, particularly for renal diseases, was high in both screened cases and patients with Itai-itai disease (12.01 (3.92 to 36.78) and 19.49 (6.43 to 59.09), respectively). Similarly, the HR for digestive diseases, particularly gastrointestinal (GI) tract diseases, was significantly increased in patients with Itaiitai disease and screened cases (5.09 (1.20 to 21.60) and 13.79 (3.87 to 49.10$)$, respectively). The increased HRs for respiratory diseases (mainly pneumonia) and cardiovascular diseases (particularly ischaemic heart disease) were statistically significant only for Itai-itai disease. The increased HR for all malignant neoplasms was not significant in either patients or screened cases, and the HR for colorectal cancer was significantly increased only in screened cases.

\section{Mortality for primary causes of death during the first 10 years}

During the first 10-year observation period, the primary cause of death was also respiratory diseases; however, the second most common causes of death among patients with Itai-itai disease were digestive disease (13 deaths) and cardiovascular disease (13 deaths) (table 3). More than $75 \%$ of the deaths for respiratory diseases and approximately $85 \%$ of the deaths for digestive diseases were observed in the first 10 years. All deaths from respiratory diseases were attributable to pneumonia and all digestive diseases were GI tract diseases. Although the HR for pneumonia was similar across all years of follow-up (4.77 (2.44 to 9.33)), the increased HR for GI tract diseases among patients with Itai-itai disease was higher (37.1 (4.81 to 286.0)) in the first 10 years compared with that in all 26 years (19.49 (6.43 to 59.09)). However, in 
Table 2 Adjusted HRs for main causes of deaths in women with Itai-itai disease and screened women with renal tubular dysfunction compared with controls matched for sex, age and occupation

\begin{tabular}{|c|c|c|c|c|c|c|c|c|}
\hline \multirow[t]{2}{*}{ Groups } & \multicolumn{2}{|c|}{ Controls } & \multicolumn{3}{|c|}{ Screened cases } & \multicolumn{3}{|c|}{ Patients with Itai-itai disease } \\
\hline & D & HR & D & HR & $(95 \% \mathrm{Cl})$ & D & HR & $(95 \% \mathrm{Cl})$ \\
\hline Malignant neoplasms & 25 & 1.00 & 17 & 1.76 & (0.94 to 3.28$)$ & 11 & 1.42 & (0.69 to 2.91$)$ \\
\hline Colorectal cancer & 1 & 1.00 & 4 & 10.1 & (1.11 to 91.34$)$ & 2 & 7.57 & (0.68 to 84.87$)$ \\
\hline Cardiovascular diseases & 43 & 1.00 & 14 & 1.07 & (0.58 to 1.98$)$ & 19 & 1.87 & (1.08 to 3.24$)$ \\
\hline Cerebrovascular diseases & 45 & 1.00 & 16 & 0.99 & $(0.56$ to 1.76$)$ & 13 & 1.07 & (0.57 to 2.00$)$ \\
\hline Cerebral infarction & 25 & 1.00 & 10 & 1.07 & (0.51 to 2.25$)$ & 6 & 0.96 & (0.39 to 2.35$)$ \\
\hline Respiratory diseases & 33 & 1.00 & 11 & 1.13 & (0.56 to 2.25$)$ & 30 & 3.96 & (2.39 to 6.58$)$ \\
\hline Pneumonia and influenza & 27 & 1.00 & 7 & 0.82 & (0.36 to 1.90$)$ & 29 & 4.54 & (2.65 to 7.76$)$ \\
\hline Digestive diseases & 7 & 1.00 & 9 & 4.16 & (1.52 to 11.41$)$ & 15 & 7.77 & (3.12 to 19.36$)$ \\
\hline Cadmium poisoning & 0 & - & 0 & - & - & 18 & & \\
\hline
\end{tabular}

Covariates, age at baseline, smoking status at present (yes: 1, no: 0) and hypertension history (yes: 1, no: 0).

$D$, number of deaths.

screened cases, the increased HR for GI tract diseases was not significant in the first 10 -year observation period. The HR for renal diseases was significantly increased both in screened cases and patients with Itai-itai disease (16.3 (1.86 to 142.8 ) and 20.2 (2.41 to 169.6$)$, respectively), even in the first 10 years.

\section{DISCUSSION}

\section{Principal findings}

In the present study, which examined direct causes of death from autopsy records, the causes of death for patients with Itai-itai disease and severe chronic Cd poisoning were distinguished. The increased mortality in patients with Itai-itai disease, particularly during the first 10-year observational period, was largely attributable to pneumonia and GI disease. Kidney and urinary tract diseases were the primary cause of death in screened cases with renal tubular dysfunction, although the mortality risk was higher among patients with Itai-itai disease compared with the screened cases. Malignant neoplasms may have contributed to increased mortality in the screened cases with renal tubular dysfunction, but not in patients with Itai-itai disease, suggesting that $\mathrm{Cd}$ toxicity may not exhibit a dose-dependent effect on cancer mortality.

Table 3 Adjusted HRs for main causes of deaths during the first 10 years in women with Itai-itai disease and screened women with renal tubular dysfunction compared with controls matched for sex, age and occupation

\begin{tabular}{|c|c|c|c|c|c|c|c|c|}
\hline \multirow[t]{2}{*}{ Groups } & \multicolumn{2}{|c|}{ Controls } & \multicolumn{3}{|c|}{ Screened cases } & \multicolumn{3}{|c|}{ Patients with Itai-itai disease } \\
\hline & D & HR & D & HR & (95\% Cl) & D & HR & (95\% Cl) \\
\hline Malignant neoplasms & 11 & 1.00 & 8 & 1.88 & (0.75 to 4.70$)$ & 6 & 1.25 & (0.46 to 3.40$)$ \\
\hline Cerebrovascular diseases & 23 & 1.00 & 11 & 1.35 & (0.65 to 2.80$)$ & 7 & 0.88 & (0.38 to 2.07 ) \\
\hline Respiratory diseases & 15 & 1.00 & 4 & 0.95 & (0.31 to 2.88$)$ & 23 & 4.47 & (2.32 to 8.62$)$ \\
\hline Digestive diseases & 3 & 1.00 & 6 & 4.16 & (1.52 to 11.41$)$ & 13 & 13.1 & (3.70 to 46.45 ) \\
\hline Gastrointestinal tract diseases & 1 & 1.00 & 3 & 8.97 & (0.92 to 87.14$)$ & 13 & 37.1 & (4.81 to 286.0$)$ \\
\hline Kidney and urinary tract diseases & 1 & 1.00 & 6 & 18.9 & (2.24 to 160.0$)$ & 7 & 23.2 & (2.83 to 190.1$)$ \\
\hline Renal diseases & 1 & 1.00 & 5 & 16.3 & (1.86 to 142.8$)$ & 6 & 20.2 & (2.41 to 169.6$)$ \\
\hline Cadmium poisoning & 0 & - & 0 & - & - & 15 & & \\
\hline
\end{tabular}

Covariates, age at baseline, smoking status at present (yes: 1, no: 0) and hypertension history (yes: 1, no: 0).

$D$, number of deaths. 


\section{Cadmium and its role in Itai-itai disease mortality}

Itai-itai disease is a type of acquired Fanconi syndrome, characterised by renal tubular dysfunction and osteomalaecia, induced by chronic $\mathrm{Cd}$ exposure through contaminated rice and drinking water. ${ }^{236}$ Patients with Itai-itai disease demonstrate a Cd body burden, indicated by $\mathrm{Cd}$ concentrations in the liver, that is remarkably higher (geometrical mean of $68.5 \mu \mathrm{g} / \mathrm{g}$ wet weight) than subjects in non-polluted areas (geometrical mean $10.4 \mu \mathrm{g} / \mathrm{g}$ wet weight). ${ }^{19}$ Fibrosis in the liver was more common in patients with Itai-itai disease, but liver function remained intact because of high expression of metallothionein to reduce $\mathrm{Cd}$ hepatotoxicity. ${ }^{20}$ In contrast, patients demonstrated kidney atrophy, with kidney weight $<60 \mathrm{~g}$ (half of normal kidney weight ${ }^{21}$ and showed characteristics of advanced chronic kidney disease (CKD). In particular, the renal cortex was very thin because of renal tubule destruction caused by Cd exposure, although Cd concentration in the cortex remained lower than that subjects in non-polluted areas, ${ }^{19}$ because there was inadequate tissue for Cd storage. Recently, potential effects of CKD on systemic immunity have been clarified; immunosuppression, leading to infection, is one of main immunological alterations of CKD.$^{22}$ Extensive proteinuria, resulting loss of proteins with immune functions, and impaired protein catabolism, which increases complement turnover, cause this immunosuppression. Uraemia and retention of metabolic waste further contribute to immunosuppression. Decreased Vitamin D and uraemic intestinal barrier dysfunction result in systemic inflammation. These immunological alterations of CKD may be observed in patients with Itai-itai disease, causing infections such as pneumonia and GI inflammation and contributing to a poor prognosis.

\section{Autopsy records and histological studies of patients with Itai-itai disease}

In the present study, 27 patients who underwent autopsy (93\% of 29 autopsy cases of Itai-itai disease with $\mathrm{Cd}$ poisoning registered as the cause of death in vital statistics data) died early during the observation period (less than 10 years). The most common direct causes of death in these patients were bronchopneumonia/pneumonia (10 deaths, $37 \%$ of the patients) and GI tract diseases (nine deaths, $33 \%$ of the patients) including haemorrhage and ulcers (see online supplementary table 2). These data were collected from a study of the direct causes of death listed in the autopsy records of 98 patients with Itai-itai disease performed in Toyama University Hospital by Kitagawa. ${ }^{5}$ These autopsy records showed direct causes of death of 75 women with Itai-itai disease: GI tract diseases in 25 cases $(33.3 \%)$, bronchitis and pneumonia in 20 cases $(26.7 \%)$, kidney and urinary tract diseases in 9 cases $(12.0 \%)$ and malignant neoplasms in 6 cases $(8.0 \%){ }^{5}$ Additionally, 14 patients (56\% of GI tract diseases cases) died from ulcers in the stomach, duodenum and rectum and 6 patients (24\% of GI tract diseases cases) died from haemorrhagic inflammation of the oesophagus, sigmoid colon and rectum. These data are consistent with results of main causes of deaths in patients with Itai-itai disease in the present study, even if the direct cause of death of 18 patients was still Cd poisoning according to vital statistics data. These findings further suggest that typical women with Itai-itai disease died earlier from pneumonia and haemorrhagic ulcer and inflammation, owing to stress and debility resulting from prolonged ill health combined with chronic pain and severe renal anaemia due to Cd exposure.

In 1972, internal medicine specialists in Toyama Prefecture hospital investigated the GI tracts of patients with Itai-itai disease and a history of intestinal erosion/ ulcer, identifying a remarkably atrophic mucosa in these patients. ${ }^{23}$ Additionally, they reported malabsorption of oleic acid or triolein in these patients, suggesting that patients with Itai-itai disease demonstrate an enteropathy similar to gluten enteropathy, leading to vitamin D malabsorption and the secondary osteomalaecia. ${ }^{23}$ This suggested enteropathy in patients with Itai-itai disease may be consistent with the frequent deaths from GI tract diseases of patients in the present study.

\section{Previous mortality studies of residents in Cd-polluted areas} in Japan, including patients with Itai-itai disease

Previous mortality studies of patients with Itai-itai disease and residents with renal tubular dysfunction were conducted in the Jinzu River basin, Toyama, Japan. Kawano et $a l^{7}$ and Nakagawa $e t a l^{\beta}$ followed patients with Itai-itai disease for 15 and 20 years, respectively, reporting an increased mortality and shortened life-span compared with inhabitants matched for sex and age with neither proteinuria nor glucosuria residing in the same polluted area. Matsuda et al conducted another 15-year follow-up of residents aged $\geq 40$ years, including patients with Itai-itai disease, living in highly polluted villages and participated in the survey conducted between 1967 and 1968. They reported a significantly increased mortality risk ratio of the subjects with proteinuria and/or glucosuria, compared with subjects without urinary findings in both sexes. ${ }^{24}$ Other mortality studies of residents with increased urinary $\beta_{2}-\mathrm{MG}$ in three different Cd-polluted areas in Japan also provided strong support for poor prognosis of cases of renal tubular dysfunction induced by Cd exposure. ${ }^{1011} 1325$

To clarify the causes of death in residents in the Jinzu River basin, Toyama, including patients with Itai-itai disease, we previously performed a 26-year follow-up study. The participants were residents who underwent the first stage of urinary examinations for proteinuria and glucosuria for Itai-itai disease screening in Toyama prefecture (primary cohort study). ${ }^{18}$ Based on the data collected, we reported mortality HRs for each cause of death identified using vital statistics data. Among the 267 women suspected of having renal tubular dysfunction based on the presence of glucoproteinuria, the mortality was increased from malignant neoplasms (HR 1.64), ischaemic heart diseases (HR 3.79) and renal diseases (HR 
23.2) after adjusting for age at baseline, smoking status and history of hypertension. ${ }^{18}$ In the present analysis, HRs from ischaemic heart diseases (HR 3.00) and renal diseases (HR 19.5) were also significantly increased, but increased HRs from malignant neoplasms (HR 1.42) were not significant in patients with Itai-itai disease exposed to $\mathrm{Cd}$ at higher levels compared with female residents with glucoproteinuria. In the Cd-polluted Kakehashi River basin in Japan, we have also reported higher mortality risks from renal disease among residents with renal tubular dysfunction, indicated by increased urinary $\beta_{2}$-MG in both sexes, ${ }^{10}{ }^{11}$ but no increased mortality for ischaemic heart diseases was found in the Kakehashi River basin. Therefore, it was suggested that mortality risk for renal disease was increased in all residents with renal tubular dysfunction induced by Cd exposure, including patients with Itai-itai disease. Furthermore, residents with renal tubular dysfunction, except patients with Itai-itai disease, might be at a risk for increased cancer mortality, because mortality risk for colorectal cancer was significantly increased only in screened cases of renal tubular dysfunction. Further analysis of all subjects with any urinary findings in the primary cohort will be required to clarify the effects of $\mathrm{Cd}$ exposure on cancer mortality. $\mathrm{Cd}$ is classified as a human carcinogen by the $\operatorname{IARC}^{1516}$ and an increased risk of lung cancer and renal cancer were reported in residents living in high Cd-exposure areas in Belgium. ${ }^{1426}$

The HRs for respiratory diseases and digestive diseases were also significantly increased in the residents with glucoproteinuria in the primary cohort study, ${ }^{18}$ but they were much lower (HR 1.75 and 2.96, respectively) than those in the patients with Itai-itai disease in the present analysis (HR 3.96 and 7.77, respectively). Moreover, the HR for GI tract diseases in patients with Itai-itai disease was 37.1 during the first 10 years, while it was 13.8 during the 26-year follow-up period. These results suggested that respiratory diseases and digestive diseases, particularly pneumonia and GI tract disease, are more specific causes of death in typical patients with Itai-itai disease.

\section{Previous mortality studies of the causes of death in workers exposed to $\mathrm{Cd}$ and male patients with Itai-itai disease}

In factory workers exposed to Cd, only one or two cases $(5 \%-8 \%)$ consisting of osteomalaecia combined with renal tubular dysfunction have been reported in Europe. ${ }^{27} 28 \mathrm{~A}$ high exposure level was found in industrial workers, but the prevalence of osteomalaecia was not high, presumably because the workers were all men. In the 26-year follow-up survey in Jinzu River basin (the primary cohort), the patients with Itai-itai disease included five men $(0.15 \%$ of male subjects) and 142 women (3.6\% of female subjects). The cause of death for all five men was $\mathrm{Cd}$ poisoning in vital statistics data and four of them underwent autopsy at Toyama University Hospital. The direct causes of death in autopsy records were respiratory diseases for three patients (two cases of pneumonia and one of emphysema) and tuberculosis for one patient, suggesting that respiratory diseases may be the main cause of death. In the follow-up surveys in factory workers exposed to $\mathrm{Cd}$ in Europe, ${ }^{29-31}$ it was suggested that mortality increased because of renal diseases and malignant neoplasms, such as lung cancer and prostate cancer. However, no significant increased mortality risk for malignant neoplasms was found in men with renal tubular dysfunction (indicated by glucoproteinuria) in the primary cohort study ${ }^{18}$ nor in men with increased urinary $\beta_{2}-M G$ residing in the Kakehashi River basin, another Cd-polluted area in Japan. ${ }^{101113}$

\section{Strengths and limitations}

The present study is the first report to clarify the final disease stages of patients with Itai-itai disease who suffered from severe renal tubular dysfunction and osteomalaecia. However, 184 patients with Itai-itai disease who died before the starting baseline survey in 1979 and 41 patients who died from 1979 to 1981 were not included as subjects of the primary cohort study, because the baseline survey was conducted from 1979 to 1984 . Autopsy was generally performed in Toyama University Hospital after 1979 , but only 12 autopsy cases were reported between 1955 and 1977. ${ }^{4}$ Therefore, the present study is limited in the recruitment of patients with Itai-itai disease who died in the 1970s. Matsuda et al conducted a 15-year follow-up survey targeting highly exposed residents in the Jinzu River basin, including patients with Itai-itai disease who died in the 1970s before our baseline survey, but they only reported increased mortality risk ratio for all causes of death in the residents with renal tubular dysfunction. ${ }^{11}$

Shigematsu et al. retrospectively investigated mortality, indicating the causes of death, in all women residing in seven villages endemic for Itai-itai disease between 1948 and 1977, including 17469 women on average between 1950 and 1970. Sixty cases were reported as direct deaths from Itai-itai disease and 13 deaths were reported to be related to Itai-itai disease. ${ }^{32}$ They also found 87 deaths related to neuralgia, which is a rare cause of death in other areas. These data suggested that the causes of death in the many patients with Itai-itai disease before our study may be Cd poisoning or neuralgia. They also reported standardised mortality ratios (SMRs) to indicate excess deaths for specific causes in the polluted area, but the subjects of their survey were residents of all ages, including infants and children (during the study period, the child population ranged between $25 \%$ and $35 \%$ ) and SMRs could not reflect causes of deaths in older residents including patients (the ageing population ranged between $5 \%$ and $7 \%$ of all population). Taken together, we concluded that a mortality study based on vital statics has limitations in distinguishing the prognosis of patients with Itai-itai disease who died before the start of the baseline survey in 1979-1984, because the causes of death of patients with Itai-itai disease may be listed as $\mathrm{Cd}$ poisoning or neuralgia in death certificates. In future, data linkage of life status with clinical records is necessary to clarify end stages of the life of typical patients with Itai-itai disease 
suffered from the severest Cd poisoning ever reported in the world.

\section{CONCLUSION}

Among patients with Itai-itai disease suffering from severe chronic Cd poisoning, pneumonia and GI tract diseases, possibly related to the general prostration of them, contributed to increased mortality risk. Kidney and urinary tract diseases were the main causes of death of the screened cases of renal tubular dysfunction, including cases of Itai-itai disease, but these were not specific for typical patients with Itai-itai disease.

Acknowledgements The authors thank Prof. Yoshikazu Nishino and Dr. Keiko Aoshima for their valuable advice during analysis.

Contributors MN and HN participated in the design and coordination of the study. $\mathrm{MN}$, KN and TK carried out the survey for baseline data collection and preparation of survival data. HN and YS performed the statistical analysis. MN and HN prepared the draft for the manuscript. All authors read and approved the final manuscript. All authors contributed to the interpretation of the results and critical revision of the manuscript for important intellectual content and approved the final version of the manuscript.

Funding This work was supported by grant for aids from Agency of Environment for Health effects due to Heavy Metal exposure 2009-12 and 2013-15. The funder has no role in: the study design; the collection, analysis or interpretation of data; the writing of the report or in the decision to submit the article for publication.

Competing interests None declared.

Patient consent Impossible consent

Ethics approval The study protocol was approved by the institutional review boards of the Kanazawa Medical University, Japan (registration no. 212).

Provenance and peer review Not commissioned; externally peer reviewed.

Data sharing statement We have no data for sharing.

Open Access This is an Open Access article distributed in accordance with the Creative Commons Attribution Non Commercial (CC BY-NC 4.0) license, which permits others to distribute, remix, adapt, build upon this work non-commercially, and license their derivative works on different terms, provided the original work is properly cited and the use is non-commercial. See: http://creativecommons.org/ licenses/by-nc/4.0/

(C) Article author(s) (or their employer(s) unless otherwise stated in the text of the article) 2017. All rights reserved. No commercial use is permitted unless otherwise expressly granted.

\section{REFERENCES}

1. Friberg L, Piscator M, Nordberg G. The Itai-itai disease. In: Friberg L, Piscator M, Nordberg G, eds. Cadmium in the environment. Ohio: CRC press, 1971:111-4.

2. Nogawa K, Kido T. Itai-itai disease and health effects of cadmium. Chang LW, ed. Toxicology of metals. New York: CRCpress, 1996:353-69.

3. Aoshima K. Itai-itai disease: renal tubular osteomalacia induced by environmental exposure to cadmium?historical review and perspectives. J Soil Sci Plant Nutr 2016;62:319-26.

4. Kasuya M. Present status of Itai-itai disease patients as of January 12, 2001. Kankyo Hoken Report;2002:41-54.

5. Kitagawa M. A review and database construction of autopsy findings of patients with Itai-itai disease for future medical studies. Kankyo Hoken Report 2002;68:21-37.

6. Aoshima K. [ltai-itai disease: cadmium-induced renal tubular osteomalacia]. Nihon Eiseigaku Zasshi 2012;67:455-63.
7. Kawano S, Nakagawa $\mathrm{H}$, Okumura $\mathrm{Y}$, et al. A mortality study of patients with Itai-itai disease. Environ Res 1986;40:98-102.

8. Nakagawa $\mathrm{H}$, Tabata M, Morikawa $\mathrm{Y}$, et al. High mortality and shortened life-span in patients with Itai-itai disease and subjects with suspected disease. Arch Environ Health 1990;45:283-7.

9. Lauwers R, De Wals P. Environmental pollution by cadmium and mortality from renal diseases. Lancet 1981;1:383.

10. Nakagawa H, Nishijo M, Morikawa $Y$, et al. Increased urinary $\beta 2-$ microglobulin and mortality rate by cause of death in a Cadmiumpolluted area. Environ Health Prev Med 1996;1:144-8.

11. Nishijo M, Morikawa $\mathrm{Y}$, Nakagawa $\mathrm{H}$, et al. Causes of death and renal tubular dysfunction in residents exposed to cadmium in the environment. Occup Environ Med 2006;63:545-50.

12. Elliott $\mathrm{P}$, Arnold R, Cockings $\mathrm{S}$, et al. Risk of mortality, cancer incidence, and stroke in a population potentially exposed to cadmium. Occup Environ Med 2000;57:94-7.

13. Li Q, Nishijo M, Nakagawa $\mathrm{H}$, et al. Relationship between urinary cadmium and mortality in habitants of a cadmium-polluted area: a 22-year follow-up study in Japan. Chin Med J 2011;124:3504-9.

14. Nawrot $\mathrm{T}$, Plusquin $\mathrm{M}$, Hogervorst $\mathrm{J}$, et al. Environmental exposure to cadmium and risk of cancer: a prospective population-based study. Lancet Oncol 2006; 7:119-26.

15. International Agency for Research on Cancer. Cadmium and cadmium compounds. IARC monograph. . Lyon: International Agency for Research on Cancer, 1993:vol. 58. 119-237.

16. International Agency for Research on Cancer. Cadmium and cadmium compounds. IARC monograph. . Lyon: International Agency for Research on Cancer, 2012:vol. 100C. 121-45.

17. Japan Public Health Association Cadmium Research Committee. Report on studies of health effects of cadmium, appendices; health survey in inhabitants living in cadmium polluted areas. Kankyo Hoken Report 1989;56:69-345.

18. Maruzeni S, Nishijo M, Nakamura K, et al. Mortality and causes of deaths of inhabitants with renal dysfunction induced by cadmium exposure of the polluted Jinzu River basin, Toyama, Japan; a 26-year follow-up. Environ Health 2014;13:18.

19. Honda R, Nogawa K. Cadmium, zinc and copper relationships in kidney and liver of humans exposed to environmental cadmium. Arch Toxicol 1987:59:437-42.

20. Baba H, Tsuneyama K, Yazaki M, et al. The liver in Itai-itai disease (chronic cadmium poisoning): pathological features and metallothionein expression. Mod Pathol 2013;26:1228-34.

21. Yasuda M, Miwa A, Kitagawa M. Morphometric studies of renal lesions in Itai-itai disease: chronic cadmium nephropathy. Nephron 1995;69:14-19.

22. Kurts $\mathrm{C}$, Panzer $\mathrm{U}$, Anders $\mathrm{HJ}$, et al. The immune system and kidney disease: basic concepts and clinical implications. Nat Rev Immunol 2013;13:738-53.

23. Murata I, Nakagawa S, Hirono T. Clinical course of Itai-itai disease. Kankyo Hoken Report 1972;11:132-9.

24. Matsuda T, Kobayashi E, Okubo Y, et al. Association between renal dysfunction and mortality among inhabitants in the region around the Jinzu river basin polluted by cadmium. Environ Res 2002;88:156-63.

25. Arisawa $\mathrm{K}$, Uemura $\mathrm{H}$, Hiyoshi $\mathrm{M}$, et al. Cause-specific mortality and cancer incidence rates in relation to urinary beta2-microglobulin: 23-year follow-up study in a cadmium-polluted area. Toxicol Lett 2007;173:168-74.

26. II'yasova D, Schwartz GG. Cadmium and renal cancer. Toxicol Appl Pharmacol 2005;207:179-86.

27. Adams RG, Harrison JF, Scott P. The development of cadmiuminduced proteinuria, impaired renal function, and osteomalacia in alkaline battery workers. Q J Med 1969;38:425-43.

28. Kazantzis G. Renal tubular dysfunction and abnormalities of calcium metabolism in cadmium workers. Environ Health Perspect 1979;28:155-9.

29. Elinder CG, Kjellström T, Hogstedt C, et al. Cancer mortality of cadmium workers. Br J Ind Med 1985;42:651-5.

30. Ades $A E$, Kazantzis $G$. Lung cancer in a non-ferrous smelter: the role of cadmium. Br J Ind Med 1988;45:435-42.

31. Sorahan T, Esmen NA. Lung cancer mortality in UK nickel-cadmium battery workers, 1947-2000. Occup Environ Med 2004;61:108-16.

32. Shigematsu I, Minowa M, Usui T, et al. Epidemiological survey for causes of death among residents in cadmium polluted areas. Kankyo Hoken Report 1980;46:1-71. 